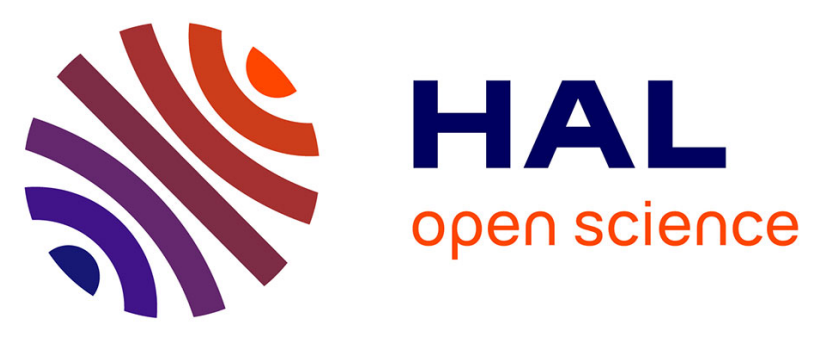

\title{
Crystalline Arrays of Pairs of Molecular Rotors: Correlated Motion, Rotational Barriers, and Space-Inversion Symmetry Breaking Due to Conformational Mutations
}

\author{
Cyprien Lemouchi, Konstantinos Iliopoulos, Leokadiya Zorina, Sergey \\ Simonov, Pawel Wzietek, Thomas Cauchy, Antonio Rodríguez-Fortea, Enric \\ Canadell, Jiři Kaleta, Josef Michl, et al.
}

\section{- To cite this version:}

Cyprien Lemouchi, Konstantinos Iliopoulos, Leokadiya Zorina, Sergey Simonov, Pawel Wzietek, et al.. Crystalline Arrays of Pairs of Molecular Rotors: Correlated Motion, Rotational Barriers, and SpaceInversion Symmetry Breaking Due to Conformational Mutations. Journal of the American Chemical Society, 2013, 135 (25), pp.9366-9376. 10.1021/ja4044517 . hal-03084635

\author{
HAL Id: hal-03084635 \\ https://hal.science/hal-03084635
}

Submitted on 19 Nov 2021

HAL is a multi-disciplinary open access archive for the deposit and dissemination of scientific research documents, whether they are published or not. The documents may come from teaching and research institutions in France or abroad, or from public or private research centers.
L'archive ouverte pluridisciplinaire HAL, est destinée au dépôt et à la diffusion de documents scientifiques de niveau recherche, publiés ou non, émanant des établissements d'enseignement et de recherche français ou étrangers, des laboratoires publics ou privés. 


\section{Crystalline Arrays of Pairs of Molecular Rotors: Correlated Motion, Rotational Barriers, and Space-Inversion Symmetry Breaking Due to Conformational Mutations}

Cyprien Lemouchi ${ }^{\dagger}$ Konstantinos Iliopoulos ${ }^{\dagger}$ Leokadiya Zorina, $^{\dagger, \#}$ Sergey Simonov, ${ }^{\dagger}, \#$ Pawel Wzietek, ${ }^{\text {II }}$ Thomas Cauchy, ${ }^{\dagger}$ Antonio Rodríguez-Fortea, ${ }^{\dagger}$ Enric Canadell, ${ }^{\S}$ Jiř́ Kaleta, ${ }^{\ddagger}$ Josef Michl, ${ }^{\ddagger}, \perp$ Denis Gindre, ${ }^{\dagger}$ Michael Chrysos, ${ }^{\dagger}$ and Patrick Batail $*^{\dagger}$

\footnotetext{
${ }^{\dagger}$ Laboratoire MOLTECH-Anjou, CNRS UMR 6200, Université d'Angers, 49045 Angers, France

\#Institute of Solid State Physics, Russian Academy of Sciences, 142432 Chernogolovka MD, Russia

"Laboratoire de Physique des Solides, CNRS and Université de Paris-Sud, 91405 Orsay, France

"Departament de Química Física i Inorgànica, Universitat Rovira i Virgili, Marcel.lí Domingo s/n, 43007 Tarragona, Spain

${ }^{\S}$ Institut de Ciència de Materials de Barcelona (ICMAB-CSIC), Campus de la Universitat Autònoma de Barcelona, 08193, Bellaterra, Spain

${ }^{\ddagger}$ Institute of Organic Chemistry and Biochemistry, Academy of Sciences of the Czech Republic, Flemingovo nám, 2, 16610 Prague 6, Czech Republic

${ }^{\perp}$ Department of Chemistry and Biochemistry, University of Colorado, Boulder, Colorado 80309-0215, United States
}

\section{ABSTRACT:}

The rod-like molecule bis((4-(4-pyridyl)ethynyl)bicyclo[2.2.2] oct-1-yl)buta-1,3-diyne, 1, contains two 1,4-bis(ethynyl)bicyclo[2.2.2] octane (BCO) chiral rotators linked by a diyne fragment and self-assembles in a one-dimensional, monoclinic $C 2 / c$ centrosymmetric structure where two equilibrium positions with large occupancy imbalance ( $88 \%$ versus $12 \%$ ) are identified on a single rotor site. Combining variable-temperature $(70-300 \mathrm{~K})$ proton spin-lattice relaxation, ${ }^{1} \mathrm{H} \mathrm{T}_{1}{ }^{-1}$, at two different ${ }^{1} \mathrm{H}$ Larmor frequencies (55 and $210 \mathrm{MHz}$ ) and DFT calculations of rotational barriers, we were able to assign two types of Brownian rotators with different activation

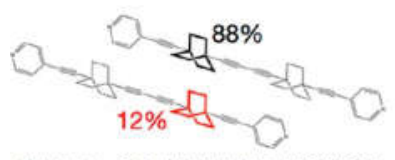
${ }^{1} \mathrm{H} T_{1}^{-1}$ : CORRELATED MOTION

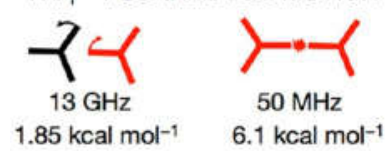

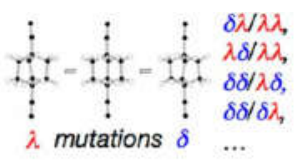

POLARIZED LIGHT

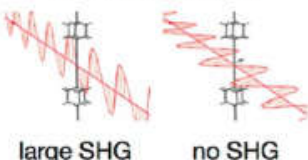
energies, 1.85 and $6.1 \mathrm{kcal} \mathrm{mol}^{-1}$, to the two ${ }^{1} \mathrm{H}$ spin-lattice relaxation processes on the single rotor site. On the basis of DFT calculations, the low-energy process has been assigned to adjacent rotors in a well-correlated synchronous motion, whereas the high-energy process is the manifestation of an abrupt change in their kinematics once two blades of adjacent rotors are seen to rub together. Although crystals of 1 should be second harmonic inactive, a large second-order optical response is recorded when the electric field oscillates in a direction parallel to the unique rotor axle director. We conclude that conformational mutations by torsional interconversion of the three blades of the BCO units break space-inversion symmetry in sequences of mutamers in dynamic equilibrium in the crystal in domains at a mesoscopic scale comparable with the wavelength of light used. A control experiment was performed with a crystalline film of a similar tetrayne molecule, 1,4-bis(3-((trimethylsilyl)ethynyl)bicyclo[1.1.1]pent-1-yl)buta-1,3-diyne, whose bicyclopentane units can rotate but are achiral and produce no second-order optical response.

\section{INTRODUCTION}

Crystalline arrays of molecular rotors with complex dynamicssuch as correlated motions and multiple rotational potentials, ${ }^{1,2}$ thermal dynamics coupled to lattice elasticity with a change in the crystal birefringence response ${ }^{3}$ or coupled to the electronic response of the system as in switchable dielectrics, ${ }^{4,5}$ and the emerging phenomenon of quantum dissipation addressing the difference of dynamics of the rotors in solids with different electrical properties ${ }^{6}$ - are of intense current interest in the field of artificial molecular machines, ${ }^{7}$ with applications in materials science ${ }^{3-6}$ and nanotechnologies. ${ }^{8}$ Here we report the discovery and subsequent designed synthesis of a molecular $\operatorname{rod}^{9}$ (1, Chart 1) with unique features: (i) it contains two Brownian rotators linked by a diyne fragment and (ii) it selfassembles into a one-dimensional crystalline array with spaceinversion symmetry (space group $\mathrm{C} 2 / \mathrm{c}$ ) (as expected for a racemic compound). The moving parts in $\mathbf{1}$ are chiral 1,4bis(ethynyl)bicyclo[2.2.2] octane (BCO) rotors ${ }^{6,10,11}$ with rotational and torsional degrees of freedom (Chart 2). An in-depth 


\section{Chart 1}

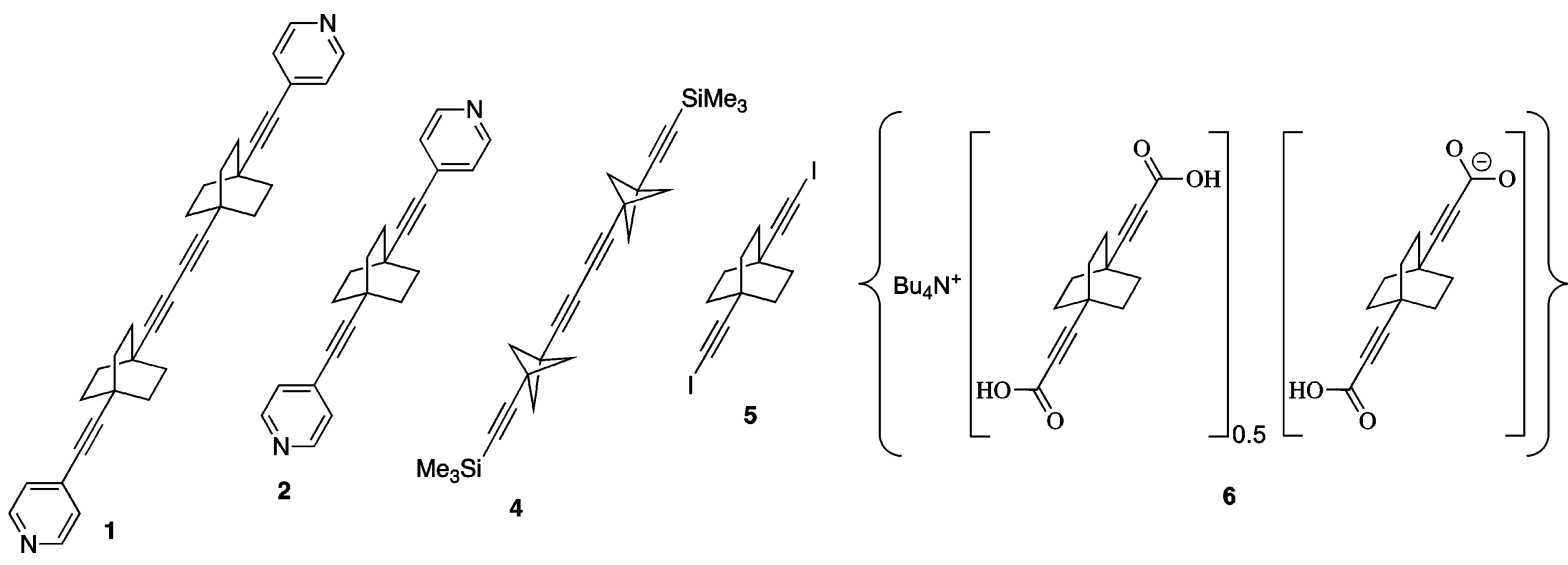

analysis of the single-crystal structure (with only one independent rotor) and variable-temperature (VT) ${ }^{1} \mathrm{H}$ spinlattice relaxation $\left(T_{1}^{-1}\right)$ data acquired on a static crystalline sample of 1 between 70 and $298 \mathrm{~K}$ reveals two $T_{1}^{-1}$ processes that are different from those expected for the rotational motion of rotors in symmetric potentials assigned ${ }^{1 \mathrm{~b}, 6,11}$ to independent sites within the crystal. On the basis of the crystal structure, activation parameters, and calculations of rotor-rotor $\mathrm{H} \cdots \mathrm{H}$ interaction energies and rotational barriers, we propose that the rotational motion of any rotor is correlated to that of an identical but different rotor belonging to an adjacent molecule in close proximity, forming pairs in the lattice. Hence, this work exemplifies the benefit of fashioning a molecular rod that contains two rotators instead of only one, a rather desirable design that increases the probability that two identical but different rotors belonging to different rods are in close proximity in the solid state. As it turns out, this favors correlated rotational Brownian motion by engineering proper intermolecular rotor-rotor interactions within crystalline arrays and exploiting their symmetry by experiments, here solid-state NMR and nonlinear optics, that allow probing their anisotropy.

Indeed, we also report in this paper the remarkable and unexpected nonlinear optical activity of a single crystal of $\mathbf{1}$. Although racemic crystals of 1 should be second harmonic inactive, a large second-order optical response is recorded when the electric field oscillates in a direction parallel to the unique rotor axle director. On the basis of an analysis of the intensity of the second harmonic generation (SHG) data as a function of the angle of incidence $\varphi$ of linearly polarized laser light on an oriented single crystal of $\mathbf{1}$, we propose that conformational mutations by torsional interconversion of the three blades of the BCO units (Chart 1) break space-inversion symmetry in sequences of mutamers in dynamic equilibrium in the crystal in domains at a mesoscopic scale comparable with the wavelength of light used. This model is validated by a control experiment with a crystalline film of a similar tetrayne molecule, 1,4-bis(3((trimethylsilyl)ethynyl)bicyclo[1.1.1]pent-1-yl)buta-1,3-diyne, 4, whose bicyclopentane units can rotate but are achiral, producing no second-order optical response.

Thus, the two degrees of freedom of the BCO rotators in $\mathbf{1}$ are shown to be associated with two remarkable phenomena (Chart 2): correlated motion, revealed by $\mathrm{VT}^{1} \mathrm{H}$ nuclear spinlattice relaxation rate $1 / T_{1}$ measurements on a static crystalline sample, involves the rotational degree of freedom; and conformational mutations within mutamers in dynamic equilibrium in the crystal, whose inherent space inversion-
Chart 2
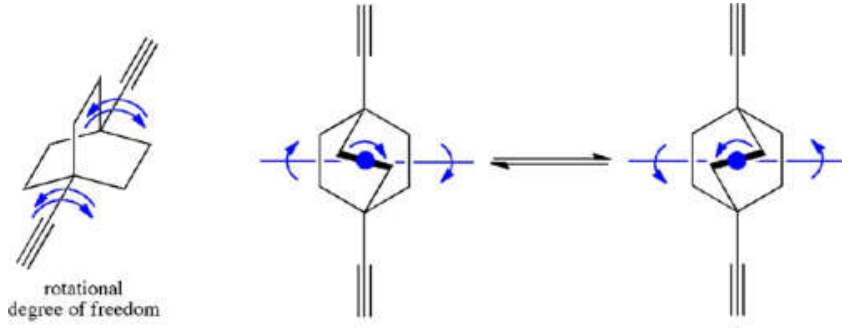

$\lambda$

$\delta$

torsional degree of freedom

symmetry breaking is probed by nonlinear optical experiments, are collective manifestations of the torsional degree of freedom.

\section{EXPERIMENTAL SECTION}

Synthesis of Bis((4-(4-pyridyl)ethynyl)bicyclo[2.2.2]oct-1-yl)buta-1,3-diyne, 1 (Schemes 1,4-6). To a solution of 1-(4pyridylethynyl)-4-ethynylbicyclo[2.2.2] octane, 3 (40 mg, $0.17 \mathrm{mmol}$ ), in $N, N$-diisopropylamine $(30 \mathrm{~mL})$ under argon were added catalytic amounts (ca. $15 \mathrm{~mol} \%)$ of $\left[\mathrm{PdCl}_{2}\left(\mathrm{PPh}_{3}\right)_{2}\right]$ and $\mathrm{CuI}(13 \mathrm{~mol} \%)$, and the mixture was degassed with argon before adding the iodine $(22 \mathrm{mg}$, $0.09 \mathrm{mmol}$ ) (Scheme 1). The reaction mixture was stirred at room temperature for $2 \mathrm{~h}$. Reaction progress was monitored by thin-layer chromatography (methylene chloride/ethanol 9:1). The reaction mixture was poured into a saturated aqueous ammonium chloride and methylene chloride $(50 \mathrm{~mL} / 50 \mathrm{~mL})$ mixture. Organics were extracted and washed with water before being dried over magnesium

Scheme 1. Synthesis of Bis(4-(4-

pyridyl)ethynylbicyclo[2.2.2] oct-1-yl)buta-1,3-diyne, 1

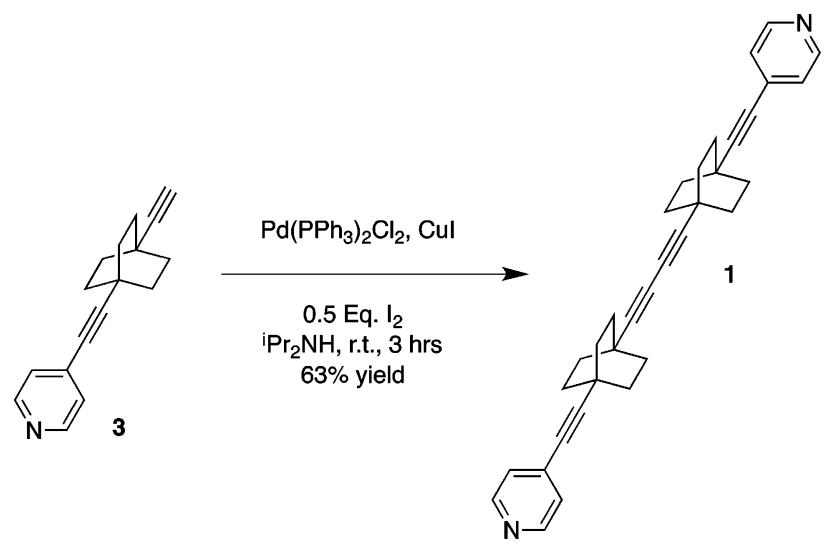


Scheme 2. Retrosynthesis of Diyne 5

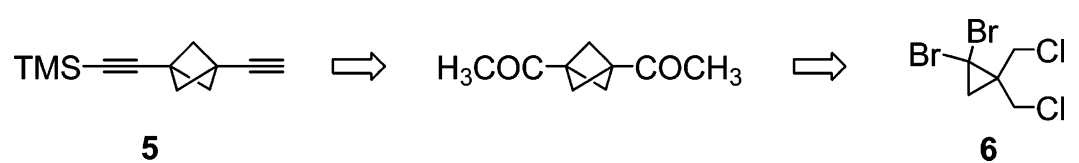

Scheme 3. Synthesis of Tetrayne 4

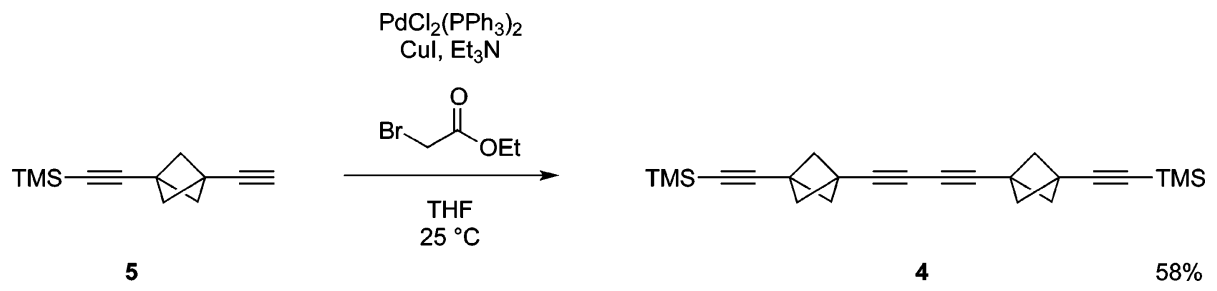

sulfate and filtered, and the solvent was removed under vacuum. Column chromatography (methylene chloride/ethanol 9:1) on silica gel afforded $25 \mathrm{mg}$ (63\% isolated yield) of $\mathbf{1}$ as a white crystalline solid, $\mathrm{mp} \operatorname{dec}>320^{\circ} \mathrm{C}$

Synthesis of 1,4-Bis(3-((trimethylsilyl)ethynyl)bicyclo[1.1.1]pent-1-yl)buta-1,3-diyne, 4 (Schemes 2 and 3). ((3Ethynylbicyclo[1.1.1]pentan-1-yl)ethynyl)trimethylsilane was prepared in five steps from 1,1-dibromo-2,2-bis(chloromethyl)cyclopropane according to previously published procedures (Scheme 2). ${ }^{12-14}$

A flame-dried Schlenk flask was charged with ((3ethynylbicyclo[1.1.1] pent-1-yl)ethynyl)trimethylsilane ${ }^{15}(390 \mathrm{mg}$, $2.071 \mathrm{mmol}), \mathrm{PdCl}_{2}\left(\mathrm{PPh}_{3}\right)_{2}(28 \mathrm{mg}, 0.040 \mathrm{mmol})$, and $\mathrm{CuI}(8 \mathrm{mg}$, $0.040 \mathrm{mmol})$. After three successive vacuum/argon cycles, dry and degassed THF $(10 \mathrm{~mL})$, triethylamine $(400 \mu \mathrm{L})$, and ethyl 2bromoacetate $(133 \mu \mathrm{L}, 1.2 \mathrm{mmol})$ were added via syringe. The reaction mixture turned black, and the dark solution was stirred for 24 $\mathrm{h}$ at room temperature. A white solid precipitated. The solution was diluted with ether $(100 \mathrm{~mL})$ and then washed with saturated aqueous $\mathrm{NH}_{4} \mathrm{Cl}(2 \times 30 \mathrm{~mL})$ and water $(1 \times 30 \mathrm{~mL})$. The yellow organic phase was dried over $\mathrm{MgSO}_{4}$. After evaporation of volatiles, the starting silylated diyne $2(142 \mathrm{mg}, 0.754 \mathrm{mmol})$ was sublimed from the crude residue using a Kugelrohr distillation apparatus $\left(120^{\circ} \mathrm{C}, 500\right.$ mTorr). Column chromatography (hexane $/ \mathrm{CH}_{2} \mathrm{Cl}_{2} 3: 1$ ) of the solid distillation residue on the silica gel provided tetrayne 4 as a white crystalline solid ( $224 \mathrm{mg}, 0.598 \mathrm{mmol}, 58 \%$ ).

Crystal Structure Determinations. A suitable crystal of 1 was coated with Paratone $\mathrm{N}$ oil, suspended in a small fiber loop, and placed on a Bruker Kappa CCD diffractometer with a graphite-monochromated Mo K $\alpha(0.71073 \AA)$ radiation. Data were collected at room temperature and $200 \mathrm{~K}$ (in a cooled nitrogen gas stream) using a series of combinations of $\varphi$ and $\omega$ scans. Data were processed using the EvalCCD program suite. ${ }^{16}$ Diffraction intensities were corrected for absorption by an empirical method with the SADABS program. ${ }^{17}$ The structure was solved by a direct method followed by Fourier syntheses and refined by a full-matrix least-squares method in an anisotropic approximation for all non-hydrogen atoms using the SHELX-97 programs. ${ }^{18} \mathrm{H}$ atoms were placed in idealized positions and refined in a riding model; $U_{\text {iso }}(\mathrm{H})$ was fixed at $1.2 U_{\text {eq }}$ of the corresponding Catom. Crystal data for 1 at $295 \mathrm{~K}: \mathrm{C}_{34} \mathrm{H}_{32} \mathrm{~N}_{2}, M_{\mathrm{r}}=468.62$, monoclinic $C 2 / c, a=31.539(6), b=8.3673(8), c=10.2441(9) \AA, \beta=97.164(8)^{\circ}$, $V=2682.3(6) \AA^{3}, Z=4, \mu=0.67 \mathrm{~cm}^{-1}, 2 \Theta_{\max }=60^{\circ}, 27924$ reflections measured, 3847 unique $\left(R_{\text {int }}=0.079\right), 1772$ with $I>2 \sigma(I)$, 218 parameters refined, $R\left(F^{2}\right)=0.0748, w R\left(F^{2}\right)=0.1632$, GOF $=$ 1.002. At $200 \mathrm{~K}$ : monoclinic $C 2 / c, a=31.333(2), b=8.3151(5), c=$ 10.2204(9) $\AA, \beta=96.300(5)^{\circ}, V=2646.7(3) \AA^{3}, Z=4, \mu=0.68 \mathrm{~cm}^{-1}$, $2 \Theta_{\max }=56^{\circ}, 20793$ reflections measured, 3152 unique $\left(R_{\text {int }}=0.055\right)$, 1844 with $I>2 \sigma(I), 164$ parameters refined, $R\left(F^{2}\right)=0.0697, w R\left(F^{2}\right)=$ $0.1657, \mathrm{GOF}=1.018$.

Variable-Temperature ${ }^{1} \mathrm{H}$ Spin-Lattice Relaxation Time $\left(T_{1}\right)$. Experiments were carried out on static crystalline samples at two different ${ }^{1} \mathrm{H}$ Larmor frequencies (55 and $210 \mathrm{MHz}$ ) and over a wide range of temperatures using a NMR spectrometer and probe built at Orsay. The probe is designed so as to reduce spurious proton signals. Samples were loaded into a small glass tube (typically $1.2-1.6 \mathrm{~mm}$ in diameter, depending on the amount of material available), around which the NMR coil was wound. ${ }^{1} \mathrm{H}$ signals were recorded using the FID following a $\pi / 2$ pulse (typically $0.8-1.5 \mu \mathrm{s}$ ), and spin-lattice relaxation was measured using the standard saturation recovery sequence. For each $T_{1}$ measurement, we recorded signals for 20 values of the relaxation delay between the saturating comb and the measuring pulse. At ambient temperature, the correlated motion with the lowenergy barrier (Figure 2c) had a frequency of $13 \mathrm{GHz}$, while the frequency for the high-energy process (Figure 2a) was $50 \mathrm{MHz}$. Comparatively, for the same rotational motion about the 1,4-axis of bicyclo[2.2.2] octane, the frequency of rotation at room temperature for the rotors in 5 (Chart 1 ) on two different crystallographic sites are 77 and $430 \mathrm{GHz}{ }^{11,19}$ Note that the rotation frequency is defined as 1/ $2 \pi \tau \mathrm{c}$, where $\tau \mathrm{c}$ is the correlation time. With this convention, according to the Kubo-Tomita expression, the maximum of the relaxation rate occurs when the rotation frequency matches the NMR (Larmor) frequency.

DFT Calculations. DFT calculation ${ }^{20}$ to evaluate the harmonic vibrational frequencies, the energy difference values associated with the different environments of the rotor, and the rotational barriers were carried out using the hybrid M06-2X functional ${ }^{21}$ and the 6-31G(d,p) basis set $^{22}$ as implemented in the Gaussian09 package ${ }^{23}$ (see Supporting Information and Figures S2-S8). Car-Parrinello molecular dynamics ${ }^{24}$ were carried out for isolated 1 with the terminal pyridines substituted by hydrogen atoms as well as for a pair of model adjacent rotors using the CPMD code. ${ }^{25}$ The simulations were performed in a cubic box with side lengths of $28 \AA \AA$ (see Supporting Information, Figure $S 9$ and movies).

Second Harmonic Generation Experiments. Each experiment is carried out using a thin, colorless plate-like single crystal mounted on a nylon loop (Hampton Research), as exemplified in Figure 3a, thereby allowing for precise positioning, a key parameter in the experiment, as well as mechanical stability. The crystal-on-a-loop ensemble is positioned on a computer-controlled, high-performance motorized X-Y-Z translation stage (XPS, Newport), where a rotational stage and a goniometric head are attached, as it is of the utmost importance for the single crystal to remain on the focal plane of the objective lenses upon successive displacements and changes of orientation. Hence, a precise 3-D positioning of the crystal is warranted prior to each measurement, while in every case the exact positioning has been verified by a CCD camera, which allowed highmagnification visualization of the crystal. No SHG loss is observed during the experiments, as the signal generated by a reference $\mathrm{BBO}$ crystal before and after passing through 1 remains unaffected. Note, in addition, that the first electronic transitions calculated by TD-DFT (see Supporting Information), be they singlet-singlet or singlettriplet, occur at $187 \mathrm{~nm}$ for BCO and $263 \mathrm{~nm}$ for $\mathbf{1}$, demonstrating that no electronic transition occurs at the wavelength of the SHG experiment, and indeed none is identified in the electronic absorption 


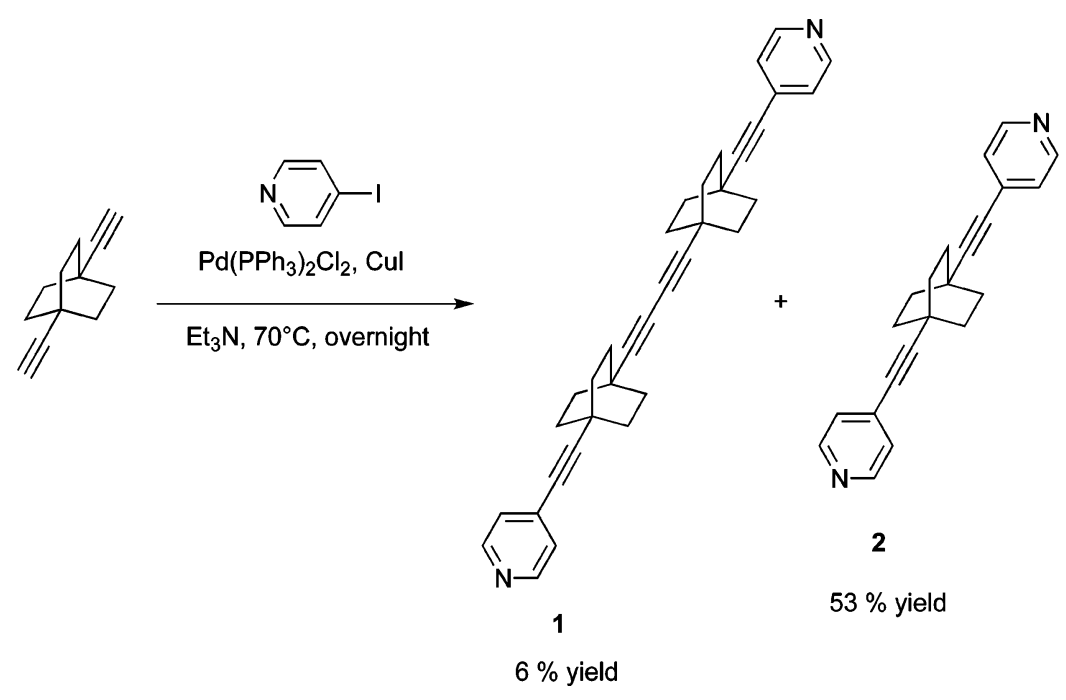

Scheme 5. Mechanism of Formation of 1,4-Bis (4'-pyridylethynyl)bicyclo[2.2.2] octane, 2, by the Reaction Described in Scheme $1^{a}$

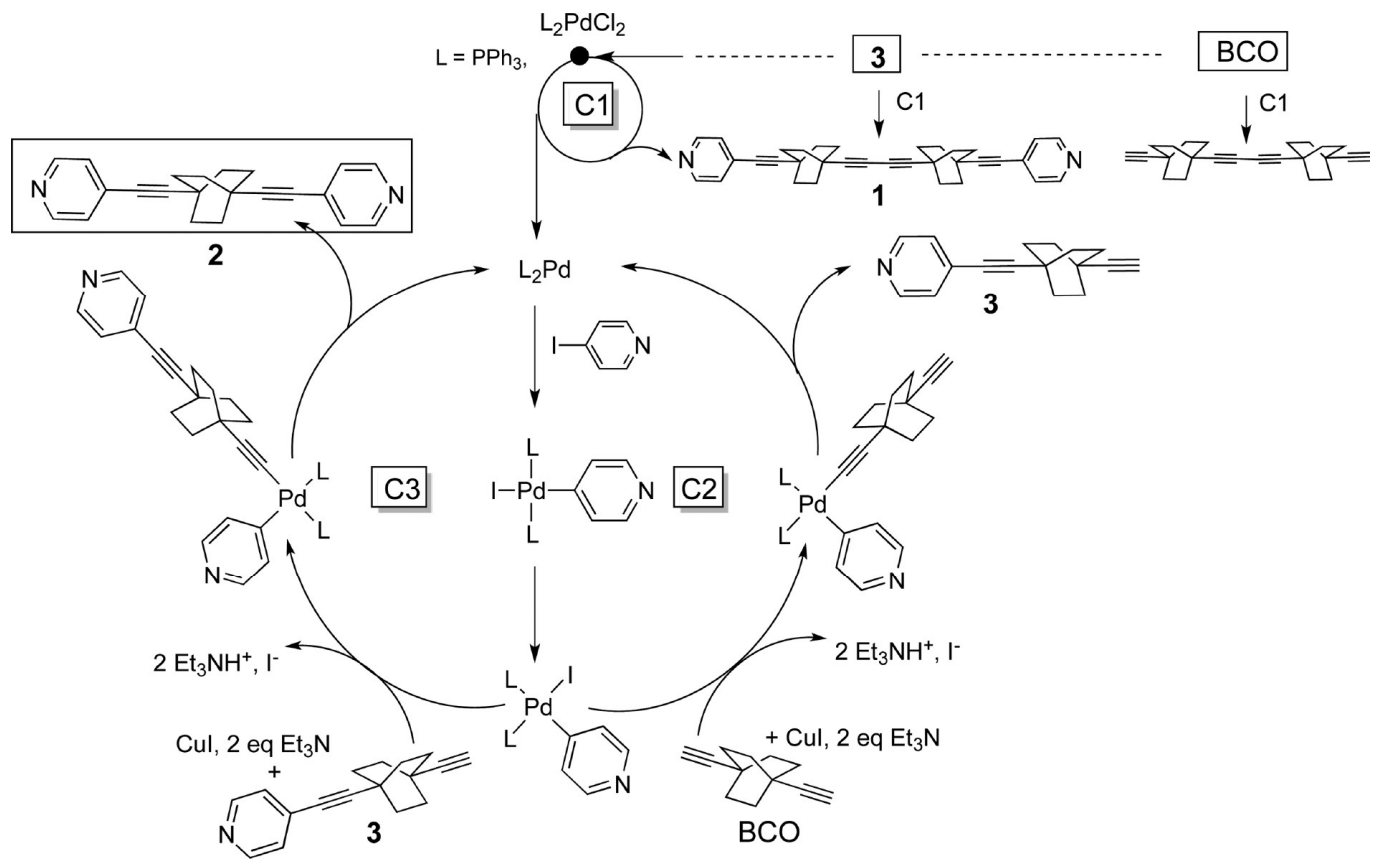

${ }^{a_{T}}$ The catalytic cycle $\mathrm{C} 1$ yields the homocoupling reaction, while $\mathrm{C} 2$ and $\mathrm{C} 3$ correspond to the heterocoupling process.

spectra recorded on crystals of $\mathbf{1}$ (Figure S12). Therefore, no resonant process is anticipated upon excitation.

\section{RESULTS AND DISCUSSION}

Designed Synthesis of 1 . In the course of the synthesis of 1,4-bis(4'-pyridylethynyl)bicyclo[2.2.2] octane, 2 (Scheme 4), by a Sonogashira coupling of $\mathrm{BCO}^{11,19}$ with 4-iodopyridine in good yields, small amounts of single crystals were obtained. The determination of their crystal structure identified bis((4(4-pyridyl)ethynyl)bicyclo[2.2.2] oct-1-yl)buta-1,3-diyne, 1, an unprecedented extended double-rotor molecule with an inner diyne fragment (Chart 1 ), which readily crystallized out, leaving the majority product $\mathbf{2}$ in the solution behind. We therefore set out to design the synthesis reported herein based on the palladium-catalyzed homocoupling ${ }^{26}$ of the dissymmetrical 1(4-pyridylethynyl)-4-ethynylbicyclo[2.2.2] octane, ${ }^{27} 3$.

The Sonogashira coupling reaction proceeds smoothly with $\mathrm{Pd}(\mathrm{II}) \mathrm{Cl}_{2}\left(\mathrm{PPh}_{3}\right)_{2}$ to yield 2 when almost no reaction occurs with $\mathrm{Pd}(0)\left(\mathrm{PPh}_{3}\right)_{4}$ (Scheme 4). Reactions were carried out in degassed solvents under an atmosphere of argon, which prevents the risk of side reactions like oxidative homocoupling, which typically would require an oxidizing agent with the presence of $\mathrm{CuCl}$ and a base like tetramethylethylenediamine (TMEDA). ${ }^{28}$ Mechanistic considerations involve three successive catalytic cycles, as discussed in Scheme 5. Note that the second cycle C2 produces the dissymmetrical 4-((4-ethynylbicyclo[2.2.2] oct-1-yl)ethynyl)pyridine, 3, which is then processed along in cycle C3 to yield 2 . Small amounts of 3 , otherwise engaged in the homocoupling reaction $\mathrm{C} 1$, also 
Scheme 6. Catalytic Cycle Accounting for the Synthesis of 1 upon a Palladium-Catalyzed Homocoupling of 1-(4Pyridylethynyl)-4-ethynylbicyclo[2.2.2] octane, 3, Inspired by Earlier Work ${ }^{26}$
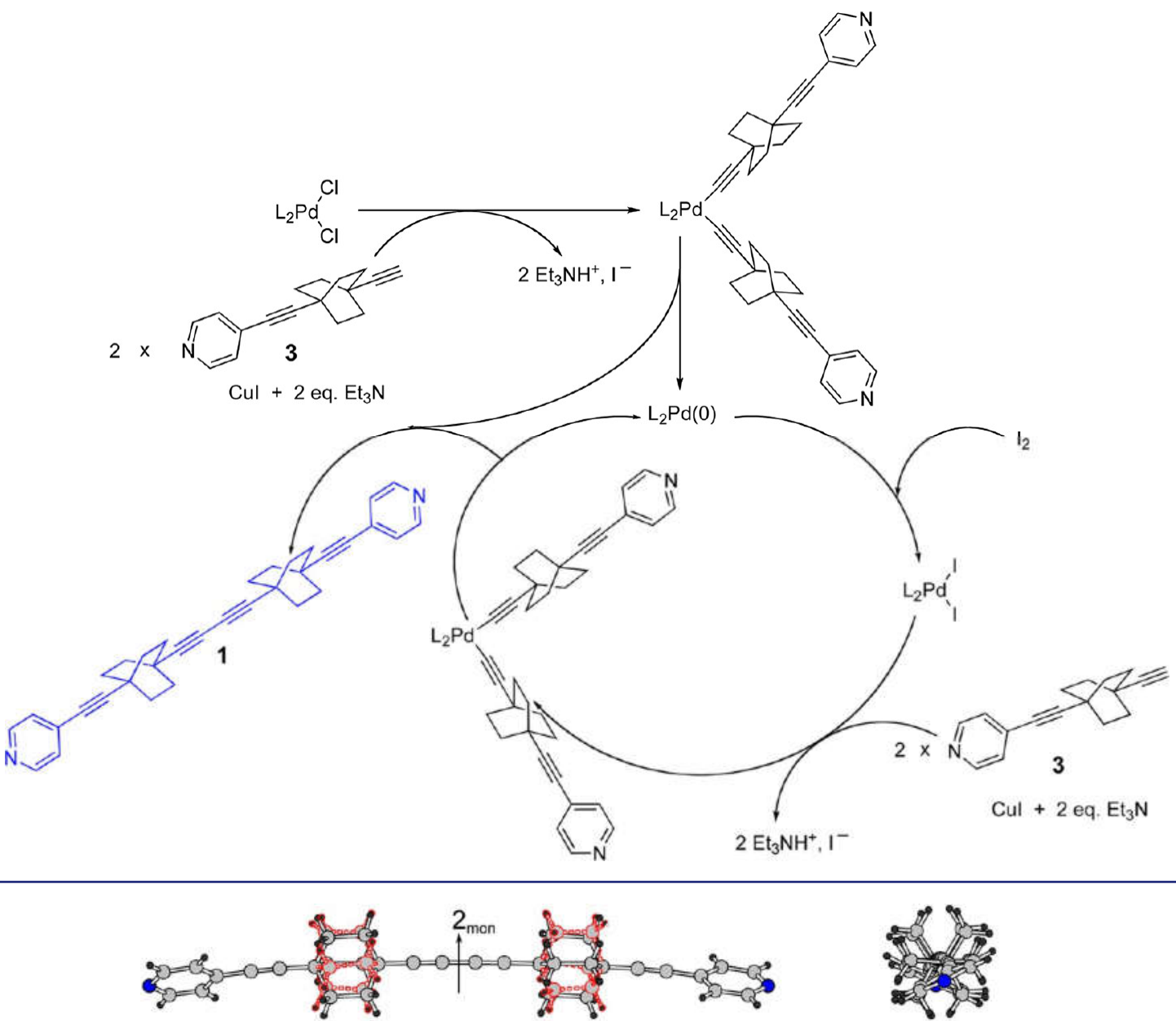

(a)

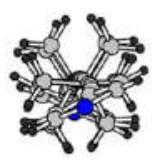

(b)

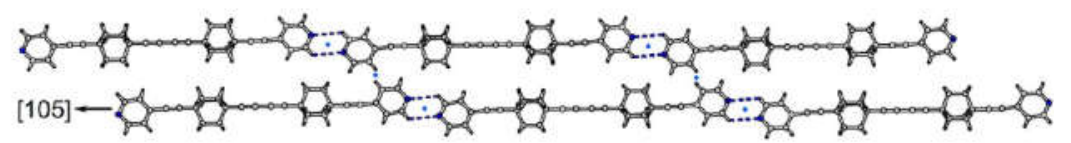

(c)

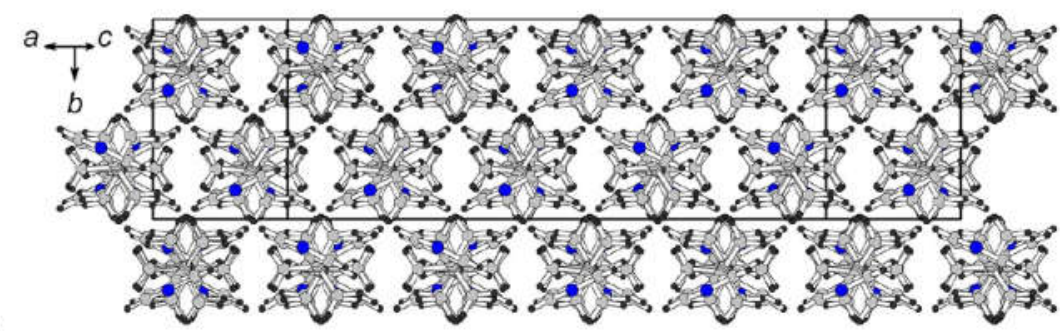

(d)

Figure 1. (a) Both majority ( $88 \%$, solid white) and minority (12\%, red dashed) equilibrium positions of the BCO rotators in the $293 \mathrm{~K}$ structure have the same handedness. The two-fold symmetry axis of the molecule in the crystal is indicated. (b) The extended molecular backbone with an inner diyne fragment has a helical shape whose left- or right-handedness is also that $(\lambda$ or $\delta)$ of the two rotators. (c) Fragment of two adjacent, onedimensional hydrogen-bonded strings running along [105] in the ac plane. The molecules are related by inversion symmetry with inversion centers $4 \mathrm{c}$ and $4 \mathrm{~d}$ represented here in blue. (d) Projection of the structure down [105], a direction close to the common director of the double rotator axles.

explain $^{26}$ the formation of $\mathbf{1}$ as it is well known that this palladium-catalyzed homocoupling process, which occurs in $\mathrm{C} 1$, proceeds in the presence of ethyl bromoacetate ${ }^{14}$ or diiodine. ${ }^{26}$ We assume that in our experimental conditions diiodine becomes available generated by the degradation of excess 4 iodopyridine. Therefore, the efficient, direct synthesis of $\mathbf{1}$ reported in Scheme 1 was designed starting from 3, using 0.5 equiv of diiodine in the presence of $\mathrm{Pd}(\mathrm{II}) \mathrm{Cl}_{2}\left(\mathrm{PPh}_{3}\right)_{2}$ as described in the literature. ${ }^{26}$ Large quantities of colorless platelike single crystals of $\mathbf{1}$ (Figure 3a) are obtained in high yields, ca. $63 \%$ (Schemes 1, 5, and 6). 
Self-Assembly of Rods 1 in a Layered Centrosymmetric Structure with a Common Director for the Rotor Axles and Two Equilibrium Positions with Large Occupancy Imbalance on a Single Rotor Site. An array of linear $\mathrm{C}-\mathrm{H} \cdots \mathrm{N}$ hydrogen-bonded chains of $\mathbf{1}$ is identified (Figure 1 and $\mathrm{S} 13$ and Table S1) in the monoclinic, $\mathrm{C} 2 / \mathrm{c}$ space group structure (see Supporting Information and Table S1). Hence, 1 has a marked one-dimensional character throughout with a common propeller axle director parallel to [105]. In the crystal, the $2.55 \mathrm{~nm}$ long molecule 1 with two BCO chiral rotors (Scheme 7), an inner diyne fragment, and two outer

Scheme 7. Chirality Switch of the Inner Rotor in 1,4Bis(ethynyl)bicyclo[2.2.2] octane

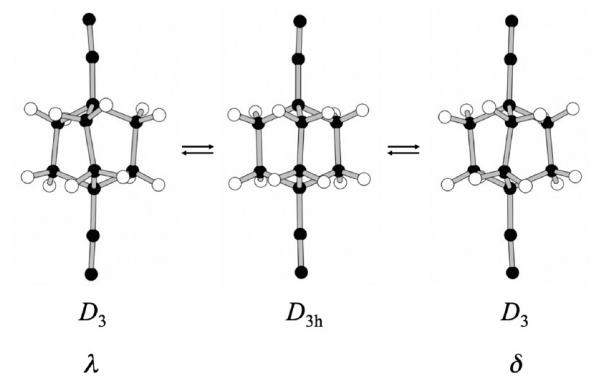

pyridine groups (Chart 1 ) has two-fold symmetry and a helical shape (Figure 1a,b). Two equilibrium positions with unusually large site occupancy imbalance are identified for the two-fold symmetry-related BCO rotators in the $293 \mathrm{~K}$ structure (Figures 1a and S1). For comparison, the site occupancy is $50 \%$ for each of the two positions on the disorder sites in $5^{11,19}$ (Chart 1 ). Specifically, the two equilibrium positions differ by a $60^{\circ}$ rotation, and their occupancy ratio was found to be $88: 12$ at room temperature. Both $88 \%$ (white solid) and 12\% (red dashed) sites of the same molecule have the same handedness, for example $\lambda$ in Figure 1a. Only the majority (88\%) position is shown in Figure $1 \mathrm{~b}, \mathrm{c}$. The minority position with the shorter residence time at room temperature is absent in the $200 \mathrm{~K}, \mathrm{C} 2$ / $c$ structure. Gas-phase studies, ${ }^{29}$ single-crystal X-ray diffraction, ${ }^{30}$ and theoretical calculations (Supporting Information) indicate that the $D_{3 h}$ structure of the inner rotor in $\mathrm{BCO}$ is a transition state with a barrier height of ca. $0.1 \mathrm{kcal} \mathrm{mol}^{-1}$ that interconnects the two $D_{3}$ structures $\lambda$ and $\delta$ upon torsional motions around the rotor blades axles.

Two ${ }^{1} \mathrm{H}$ Spin-Lattice Relaxation Processes for the Single Rotor Site. Variable-temperature ${ }^{1} \mathrm{H} T_{1}$ spin-lattice relaxation experiments ${ }^{5 b, 11,19,31}$ were conducted at two fields (Figure 2a) on a static polycrystalline sample. Two thermally activated relaxation processes are observed, defined by Arrhenius parameters derived from robust fits of the $T_{1}$ data to the Kubo-Tomita formula, ${ }^{11,19,5 b} \tau_{\mathrm{c}}=\tau_{0} \exp \left(E_{\mathrm{a}} / k T\right)$ achieved for a 1:1 ratio of the mobile protons consistent with maxima of equal heights. While the occurrence of two relaxation processes in 5 and $6^{6}$ (Chart 1 ) has typically been associated with rotors on two different crystallographic sites, the two rotors in $\mathbf{1}$ are located on identical, two-fold symmetryrelated sites. Note that the second relaxation peak cannot be ascribed to a different group such as a terminal pyridine because we would expect the two peaks to have different amplitudes. Thus, our primary view was to assume that the rotors motion is coupled and that the two frequencies that were observed are associated with two different rotational processes of the two rotors in $\mathbf{1}$. DFT calculations for an isolated $\mathbf{1}$ showed that this is not the case since only a low-frequency normal mode of 11 $\mathrm{cm}^{-1}$ associated with an out-of-phase rotation of the two rotors was found. The terminal pyridine motions are found to be practically uncoupled to this rotational motion. Indeed, the energy difference between relative orientations of $0^{\circ}$ or $60^{\circ}$ of the two rotors across the inner diyne fragment in an isolated molecule $\mathbf{1}$ is computed to be almost zero. Car-Parrinello molecular dynamics simulations at room temperature with the terminal pyridines substituted by hydrogen atoms confirm the out-of-phase motion of the two rotors and the very low rotational barrier for a discrete molecule in the gas phase (see Supporting Information). Thus, we reasoned that the large energy difference of the two thermally activated processes (Figure 2a) might be associated with different local environments of the rotor in the crystal because of the dynamic disorder over two equilibrium positions.

Rotor-Rotor Interaction and Correlated Motion of Adjacent BCO Rotors. DFT calculations carried out for a model in which one of the two rotors in $\mathbf{1}$ was in the presence of all other neighboring rotor units in the crystal making $\mathrm{H} \cdots \mathrm{H}$ contacts shorter than $2.8 \AA$ led us to the conclusion that the rotational motions of neighboring molecules must be correlated (see Supporting Information for details on the computational model). For instance, a set of five such rotor-rotor contacts shorter than $2.4 \AA$ (2.103, 2.225, 2.241, 2.278, and $2.330 \AA$ ) occurring between neighboring minority equilibrium positions within a pair of adjacent molecules in a layer (Figure 2e) penalize the system by an energy of around $5 \mathrm{kcal} \mathrm{mol}^{-1}$, which matches very well the difference in activation energies obtained in the ${ }^{1} \mathrm{H} T_{1}$ spin-lattice relaxation experiments. Destabilizing interactions associated with other combinations of majority and minority equilibrium conformations of neighboring rotors are at most $1.5 \mathrm{kcal} \mathrm{mol}^{-1}$ stronger than those in which all rotors are in the majority equilibrium conformation (Figure 2c). Indeed, the low-energy process with a $T^{-1}$ maximum at ca. 130 $\mathrm{K}$ (Figure $2 \mathrm{a}$ ) was fitted to an activation energy of $1.85 \mathrm{kcal}$ $\mathrm{mol}^{-1}(930 \mathrm{~K})$ and a pre-exponential factor (or attempt frequency) $A=1.82 \times 10^{12} \mathrm{~s}^{-1}\left(\tau_{0}=5.5 \times 10^{-13} \mathrm{~s}\right)$. Much larger values, that is, an activation energy of $6.1 \mathrm{kcal} \mathrm{mol}^{-1}$ $(3078 \mathrm{~K})$ and an attempt frequency $A=8.3 \times 10^{12} \mathrm{~s}^{-1}\left(\tau_{0}=1.2\right.$ $\times 10^{-13} \mathrm{~s}$ ), were found for the higher energy process with a $T_{1}$ minimum at ca. $330 \mathrm{~K}$.

With this in mind, we interpret the two $T_{1}^{-1}$ maxima as corresponding to the different relative motions between two $\mathrm{BCO}$ rotators, which can be thought to rub against each other just as two cog wheels that are in direct contact with one another. The process with the lower energy barrier is assigned to a well-correlated synchronous motion between the two adjacent rotors (Figure 2c), whereas the high-energy process is the manifestation of an abrupt change in their kinematics (acceleration or deceleration of one rotor), once two blades of adjacent rotors are seen to rub together (Figure 2e), and in a way analogous to a pair of sliding gear wheels needing energy to overcome this position. Actual calculation of the rotational energy barriers for the correlated synchronous and asynchronous motions of two adjacent rotors mimicking the situation in the solid led to values of 1.08 and $4.88 \mathrm{kcal} / \mathrm{mol}$, respectively (see the Supporting Information for details of the model calculations as well as for a Car-Parrinello molecular dynamics simulation at room temperature illustrating the correlation of the rotational motions). We believe that the good agreement between these rotational barriers and those estimated from the 


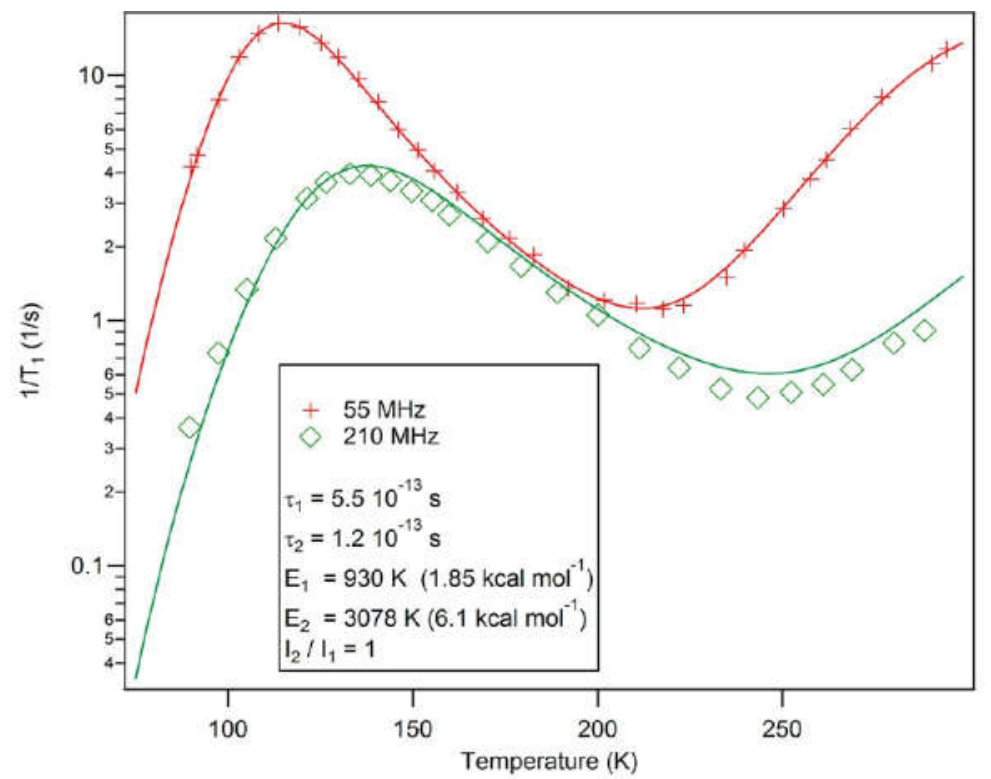

(a)

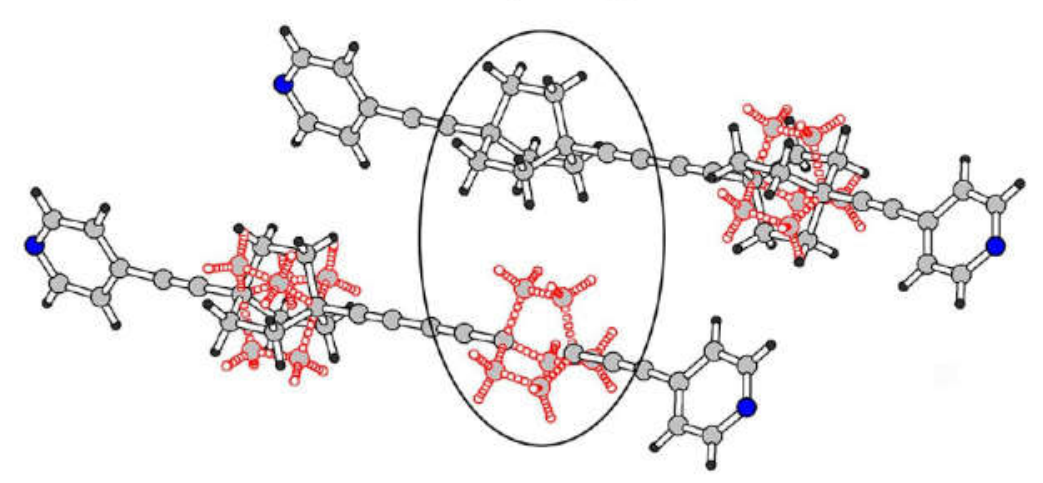

(b)

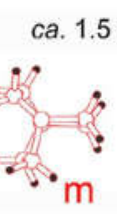

(c)

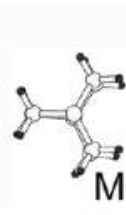

(d)

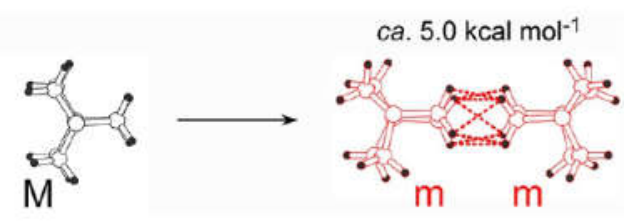

(e)

Figure 2. (a) Variable-temperature reciprocal ${ }^{1} \mathrm{H}$ spin-lattice relaxation time, ${ }^{1} \mathrm{H} \mathrm{T}_{1}{ }^{-1}$ at 55 and $210 \mathrm{MHz}$ for 1 . (b) Adjacent rotors (see also Figure $3 \mathrm{~b})$ : (c) one in a majority $(\mathrm{M})$ site and the other in a minority $(\mathrm{m})$ site, $(\mathrm{d})$ both in majority sites, and (e) both in minority sites. The dotted red lines represent the five $\mathrm{H} \cdots \mathrm{H}$ rotor-rotor contacts at 2.103, 2.225, 2.241, 2.278, and $2.330 \AA$.

${ }^{1} \mathrm{H} \quad T_{1}$ spin-lattice relaxation experiments provides strong support to our analysis of the origin of the different rotational barriers in $\mathbf{1}$.

Second-Order Optical Response Recorded When the Electric Field Oscillates in a Direction Parallel to the Unique Rotor Axle Director. With the knowledge of the motion of the chiral rotors in this compound, we decided to explore the possibility to interfere with the dielectric modulation associated with the rotor dynamics by shining a linearly polarized light on a single crystal of $\mathbf{1}$. As shown in Figure $3 \mathrm{~b}$, the rotor axle director runs approximately parallel to [105], at $55^{\circ}$ from $a^{*}$. This feature turned out to be of great significance in deciphering the nonlinear optical response measured on one single crystal, in spite of its centrosymmetric space group. The (100) face of a colorless single-crystal platelet of dimensions $400 \times 360 \mu \mathrm{m}^{2}$ and a thickness of $20 \mu \mathrm{m}$, is laid down flat attached on a nylon loop with a tiny amount of mineral oil, and so aligned that the $b$ axis is parallel to the loop's rotation axis (see Figure $3 a$ ) so that at the onset of the experiment $\left(\varphi=0^{\circ}\right)$, the laser light propagates along $a^{*}$. A first experiment was conducted by rotating the crystal around $b$ thereby allowing us to monitor the nonlinear optical response as a function of the angle of incidence $(\varphi)$, the angle between $a^{*}$ (the direction normal to (100), the larger crystal face) and the propagation axis of the incident, fundamental laser beam. Here, with the hindsight of the one-dimensional character of the structure and the crystal indexation, the variation of the SHG intensity has been investigated (Figure 4a) by rotating the rotor axle director about a set linear $\mathrm{p}$ vertical incident polarization (Figure 4). In Figure 4a the average SHG is shown as a function of the angle of incidence $\varphi$. A peak is revealed for an incident angle of about $30^{\circ}$. Remarkably, the largest nonlinear response is thus recorded when the electric field 


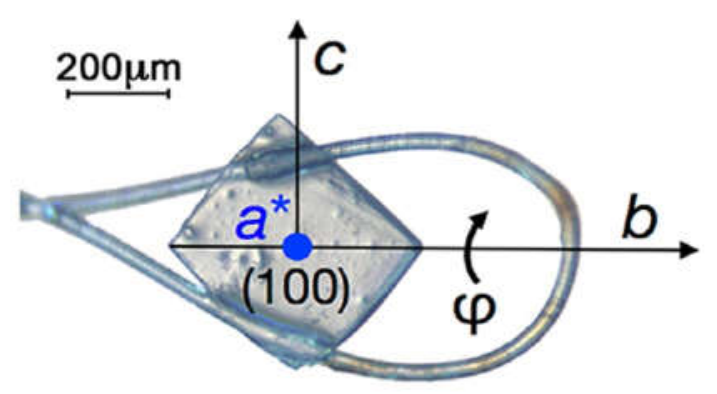

(a)

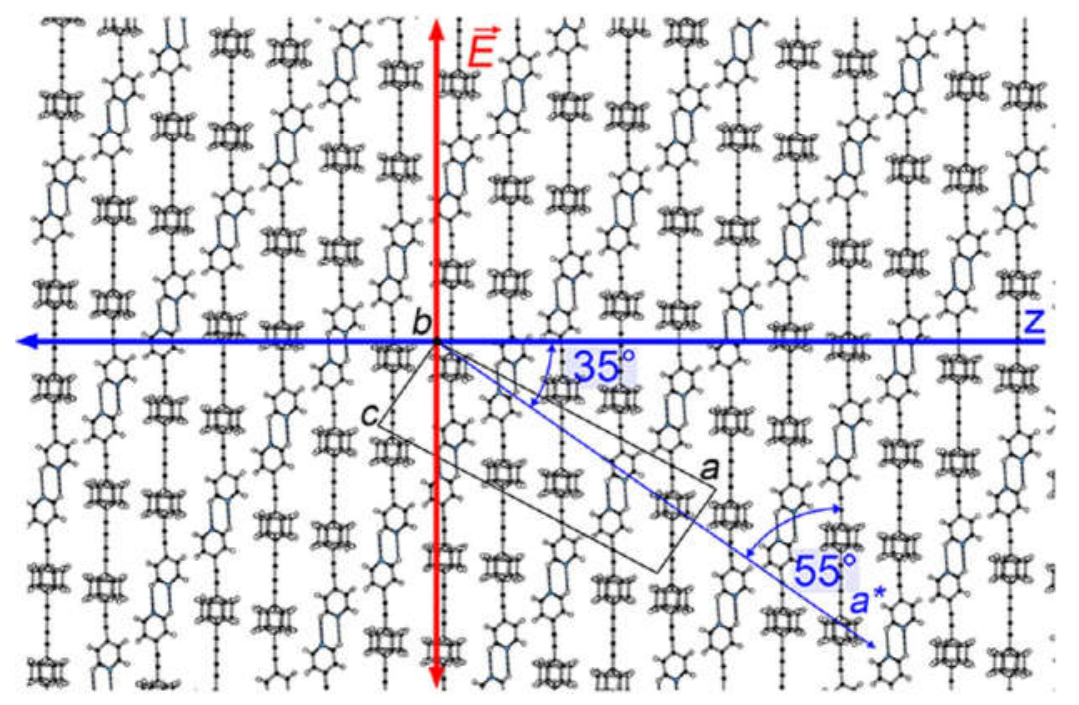

(b)

Figure 3. (a) At the onset of the experiment $\left(\varphi=0^{\circ}\right)$, the laser light propagates along $a^{*}$. (b) One single ac layer is shown here projected along $b$ with the direction of propagation of the light, $z$, parallel to $a c$, visualized by the blue solid line. At $\varphi=0^{\circ}$, for a set vertical polarization (p), the electric field oscillates in a direction normal to $a^{*}$, at $55^{\circ}$ to [105]; a rotation of the crystal by $35^{\circ}$ around $b$ causes the polarized laser light to propagate normal to the rotor axle direction, as shown. When the linear polarization is set to be vertical (p), the electric field $E$ oscillates exactly in the common direction of the rotor axles in the whole crystal.

oscillates in a direction parallel to the unique rotor axle director of the one-dimensional structure (Figures $4 \mathrm{~b}$ and $3 \mathrm{~b}$ ).

Then, the crystal was set at $\varphi=30^{\circ}$ (the position where maximum SHG has been found during the previous experiment) and a second series of measurements were carried out by recording the SHG signal for different values of $\delta$, the angle between the direction of the polarization of the electric field and the direction of the rotor axle director, as in the inset of Figure 4b. The angle $\delta$ was precisely tuned using a half-wave plate in order to keep the intensity constant during the measurements. Maximum SHG signal was obtained starting with vertical $(p)$ polarization and was found to decrease by increasing $\delta$, as shown in Figure $4 \mathrm{~b}$ for a $360^{\circ}$ variation of $\delta$. The SHG intensity maximum was retrieved for $\delta \approx 0^{\circ}$, that is again for an electric field oscillating along the rotor axle director (Figure $4 \mathrm{~b}$ ). Note that the latter direction is also the direction of the largest component of the calculated polarizability tensor of 1 (see Supporting Information). Furthermore, it is remarkable that the minimum of the fitted curve is shifted by exactly $90^{\circ}$ with respect to the maximum (occurring with $\mathrm{s}$ polarized laser beam), a configuration where the electric field now oscillates normal to the rotor axle director (Figure $4 b$ ). Hence it would appear that for any intermediate $\delta$ value, only the vertical component of the electric field vector would be efficient at producing the nonlinear signal. In other words, the larger the projection of the electric field onto the rotor axle director, the higher is the SHG efficiency.

Dynamic Equilibrium in the Racemic Crystal of Centrosymmetric Pairs of 1 . The units composing the crystal of 1 experience dynamical disorder because of the torsional motion of the three blades driving the $D_{3} \leftrightarrows D_{3 h} \leftrightarrows D_{3}$ chirality switch of the $\mathrm{BCO}$ rotor unit ${ }^{32}$ (Scheme 7 ) whose barrier is as low as $0.1 \mathrm{kcal} \mathrm{mol}^{-1}$ (Supporting Information). Let $\lambda$ and $\delta$ be the two possible $D_{3}$ conformations of a rotor (Scheme 7). With two-fold symmetry, both rotors and the helical axle (Figure 1b), have the same handedness and the whole molecule is chiral. Let then $\delta \delta$ arbitrarily be the conformation of the rotors in a molecule. Space inversion symmetry is a fundamental property of racemic crystals since it offers them the advantage of doubling the number of stabilizing interactions. As a result, for any bimolecular unit $\delta \delta$, there is a nearby molecule symmetric to this one with respect to space inversion (Figure 1c), whose rotor configurations are $\lambda \lambda$. Thus, the whole ideal crystal can be viewed as the self-assembly of molecular pairs that are all assigned to the character $\delta \delta / \lambda \lambda$. The $\delta \delta / \lambda \lambda$ will thus be the sequence of reference, i.e., that with the lowest energy. Indeed, any deviation from that sequence will be totally absent from the ideal crystal since its presence would be 

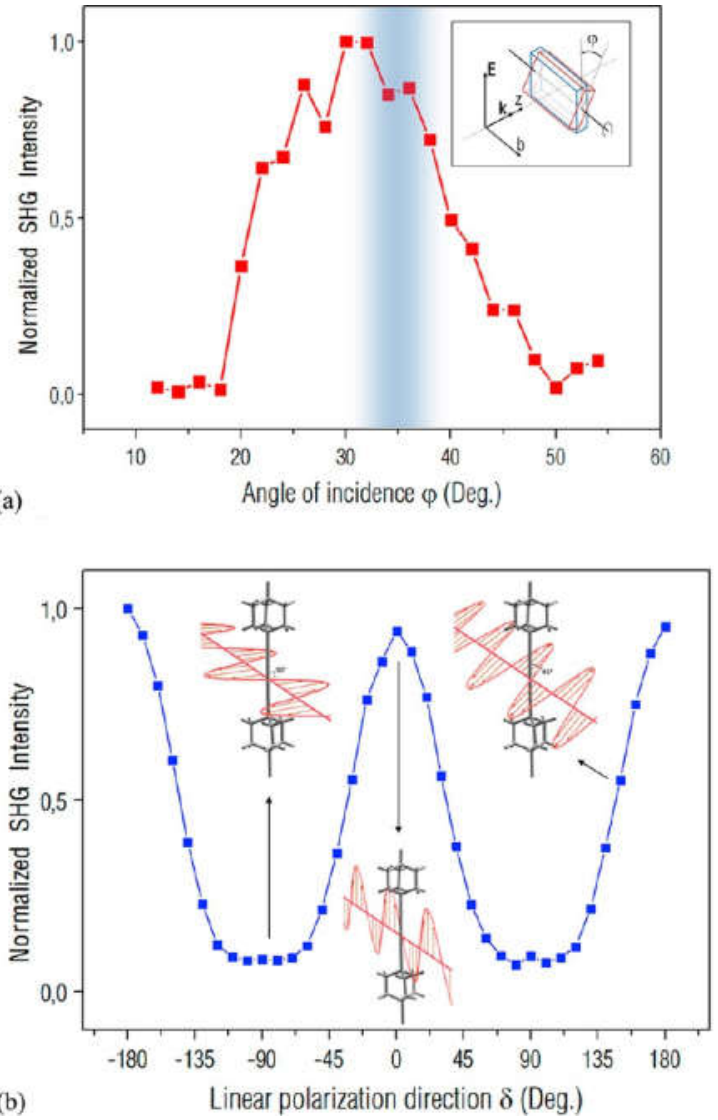

Figure 4. Nonlinear optical response of a single crystal of 1. (a) Intensity of the SHG as a function of the angle of incidence $\varphi$ defined in Figure 3a. The maximum intensity is reached for an incident angle of about $30^{\circ}$, while the soft vertical blue line shows the angle corresponding to $a^{*}\left(\right.$ about $35^{\circ}$ ). Inset: scheme of the position of the crystal after rotation ( $k$ is the wave vector of the light, $E$ is the electric field vector and $b$ is the crystal axis defined in Figure 3a). (b) Evolution of the intensity of the nonlinear optical response with $\delta$, the angle between the electric field vector $E$ associated with the linear polarization direction and the direction of the rotor axle director, as illustrated in the insets. a defect perturbing the least-action path of the self-assembly. For example, the occurrence of the symmetrical sequence $\lambda \lambda$ / $\delta \delta$ would be the worst of the defects since all four letters have been altered. Thus, only bimolecular units that are exact replica of each other, with identical handedness of the rotors and shape-complementary helical conformations (Figure 1c), can ensure the racemic character ${ }^{33}$ and thereby a minimum energy in an ideal crystal. Although such a structure is second harmonic inactive, our experiment provides compelling evidence of the opposite: a strong SHG signal was recorded from the crystal.

Conformational Mutations by Torsional Interconversion Break Space-Inversion Symmetry in Sequences of Mutamers. To pinpoint the origin of this apparent paradox we now turn our attention to real crystals and to rotors that no longer are frozen. In such a crystal, the rotors may twist from $\delta$ to $\lambda$ or from $\lambda$ to $\delta$, since the potential barrier for torsional interconversion is very low. These are defects locally breaking the two-fold symmetry of the molecules and thus the space inversion symmetry in the crystal. As a result, at the time scale of the oscillating electric field period the crystal is no longer a centrosymmetric structure, even though its X-ray structure provides apparent evidence of the opposite: careful examination of the diffraction data provided no reasons for symmetry lowering nor for additional long-range ordering of the molecules in a larger unit cell. ${ }^{34}$ The space-inversion symmetry breaking by mutations is not in conflict with the observation, since what X-rays provide is nothing else than a statistical average over all the possible configurations that are thermodynamically possible at the temperature of the experiment. Thus, sequences deviating from the sequence of reference $\delta \delta / \lambda \lambda$, in which one or several rotors have undergone conformational mutations, can appear in the crystal. Among such, the "mutamers" $\delta \lambda / \lambda \lambda, \lambda \delta / \lambda \lambda, \delta \delta / \lambda \delta, \delta \delta / \delta \lambda$, resulting from a single mutation of the ground-state sequence, have lost their inversion symmetry-a property clearly leading to second-order optical activity. Indeed, the effective mean configuration determined by X-ray diffraction for the dynamical disorder of chiral rotor units in thermodynamic equilibrium in the crystal clearly indicates that, in addition to the ground-state
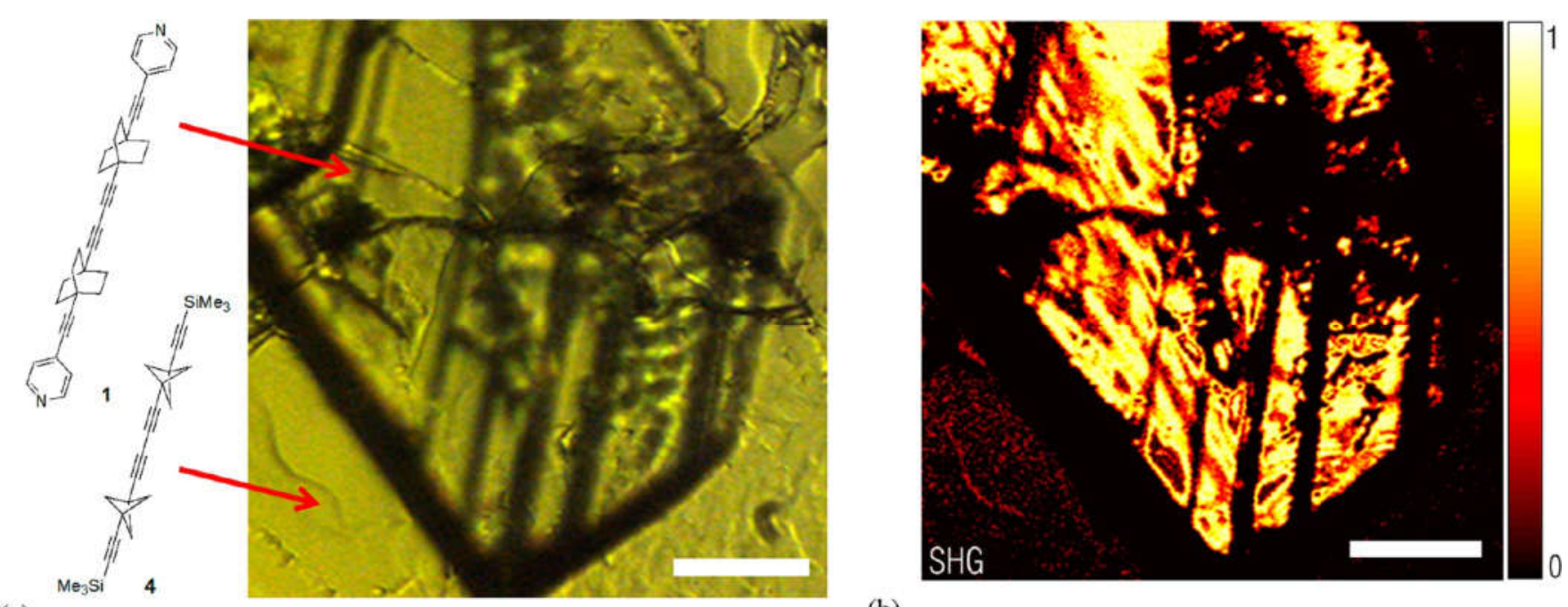

(a)

(b)

Figure 5. (a) Optical microscope image using a $\times 20$ objective lens of a crystalline film of bicyclo[1.1.1]pentane derivative, 4 with a single crystal of 1 placed on top. (b) Normalized SHG image of the same area. The scale bar for both images is $50 \mu \mathrm{m}$. 
$\delta \delta / \lambda \lambda$ centrosymmetric sequence, a whole statistical admixture of mutamers is present everywhere in the crystal. That is how the small values of the dihedral angles at 295 and $200 \mathrm{~K}$ are interpreted $^{35}$ (Figure S11) upon comparison with the much larger calculated DFT value $\left(16^{\circ}\right)$ for an isolated molecule 1 .

Whereas the sequences $\delta \lambda / \lambda \lambda, \lambda \delta / \lambda \lambda, \delta \delta / \lambda \delta$, and $\delta \delta / \delta \lambda$, in which only one character has mutated, are readily understood to be sources of SHG, higher-order sequences in which more than one character was altered must also be present in the admixture. Those mutamers cannot but sustain or even reinforce the breaking of the space inversion symmetry in the crystal, and therefore enhance its second-order optical activity. The fully altered $\lambda \lambda / \delta \delta$ sequence is an exception to this rule: in this mutamer inversion symmetry has been restored and, hence, this mutamer will be SHG-inactive. With regard to symmetry, this particular mutamer is the mirror counterpart of $\delta \delta / \lambda \lambda$, and as such, it offers itself the possibility, energetically, to locally create an environment that is favorable to a "mirroring" crystal. Although these domains in the crystal are expected to be energetically almost as stable as in a crystal in which solely replicas of $\delta \delta / \lambda \lambda$ occur, the whole structure will be globally heterogeneous on a mesoscopic scale. This scale is far smaller than the volumetric pixel used in the SHG experiment. It is clear from the above that these heterogeneities cannot but further add to the already established second-order optical activity of the material.

Control Experiment with a Similar Tetrayne Molecule Whose Bicyclopentane Units Can Rotate but Are Achiral. The fact that the strong second-order optical response that we observed is indeed due to such sequences of helixhandedness mutations of the rotors, ${ }^{36}$ is further confirmed by a control experiment (Figure 5) with a similar tetrayne molecule, 1,4-bis(3-((trimethylsilyl)ethynyl)bicyclo[1.1.1]pent-1-yl)buta1,3-diyne, 4 (Chart 1). In a crystalline film of 4 , the bicyclopentane units undoubtedly rotate but are achiral and therefore incapable of mutation. A crystalline film of 4 (with nonchiral bicyclo[1.1.1]pentane rotators) was drop-cast on a glass slide from a $\mathrm{CH}_{2} \mathrm{Cl}_{2}$ solution. A crystal of 1 was then deposited on the film. Two-dimensional SHG images (see Figure 5) were obtained by recording the SHG signal over the whole area of interest, which includes both the crystal as well as a section of the crystalline film. A large SHG signal is recorded over the crystal surface of $\mathbf{1}$ with fluctuations due to the poor optical quality of the crystal surface. In contrast, the crystalline film exhibits no second-order nonlinear optical response as expected.

\section{CONCLUSION}

We have reported an investigation of the dynamic equilibrium of chiral 1,4-bis(ethynyl)bicyclo[2.2.2] octane (BCO) rotors in designed two-rotor rods that self-assembled in one-dimensional crystalline arrays. A combined analysis of variable-temperature ${ }^{1} \mathrm{H}$ spin-lattice relaxation data, X-ray structure and calculation of rotor-rotor interaction energies as well as the rotational barriers provide evidence for the two nearest rotors in pairs of adjacent molecules to rub against each other just like two cog wheels that are in direct contact with one another. Although the whole racemic crystal can be viewed as a composition of molecular pairs of chiral rotors related by space inversion symmetry and should be second harmonic inactive, our experiment provides compelling evidence of the opposite: a strong second harmonic generation signal was recorded from the crystal. We propose that the answer to this apparent paradox is found in the very nature of mutamers that are sequences of helix-handedness mutations of the $\mathrm{BCO}$ quantum rotor units, which are present at the time scale of the oscillating electric field period. We suggest that such mutamers occur in domains with no space inversion symmetry at a mesoscopic scale comparable with the wavelength of light used. These results illustrate fundamental issues in the quantum physics of molecular systems with glassy components, ${ }^{34,35}$ potential applications in molecular opto-mechanical switches, and provide desirable virtual imaging modalities to probe the symmetry of assemblies of chiral molecular rotors, or of any molecule which can switch from one enantiomer to the other in the solid state. The conformational mutations model and the concept of mutamer disclosed herein offer an unprecedented perspective in material sciences as to the use of light in condensed phase systems to exploit the dynamic equilibrium between their chiral moving parts.

\section{ASSOCIATED CONTENT}

\section{Supporting Information}

Characterization data for 1, 2, and 4; additional crystallographic information; computational details with movies showing two rotors (si_004.avi) and double rotor (si_005.avi); SHG experiments; Figures $\mathrm{S} 1-\mathrm{S} 15$. This material is available free of charge via the Internet at http://pubs.acs.org.

\section{AUTHOR INFORMATION \\ Corresponding Author \\ patrick.batail@univ-angers.fr}

\section{Notes}

The authors declare no competing financial interest.

\section{ACKNOWLEDGMENTS}

Work at Angers was supported by the CNRS and by the Region des Pays de la Loire Grant MOVAMOL and the joint CNRSRussian Federation grants PICS 6028 and RFBR-CNRS 12-0391059. C.L. and K.I. thank the CNRS and the Région des Pays de la Loire for a Ph.D. grant and a post-doctoral grant, respectively. Work in Bellaterra and Tarragona was supported by the Spanish Ministeriode Economía y Competitividad (Projects FIS2012-37549-C05-05, FIS2009-1271-C04-03, CTQ2011-29054-C02-01 and CSD 2007-00041). Work in Prague was supported by ERC grant 227756 and the Institute of Organic Chemistry and Biochemistry, Academy of Sciences of the Czech Republic (RVO: 61388963), and work in Boulder by the U.S. National Foundation grant CHE 0848663.

\section{REFERENCES}

(1) (a) Jarowski, P. D.; Houk, K. N.; Garcia-Garibay, M. A. J. Am. Chem. Soc. 2007, 129, 3110. (b) Rodríguez-Molina, B.; Farfán, N.; Romero, M.; Méndez-Stivalet, J. M.; Santillan, R.; Garcia-Garibay, M. A. J. Am. Chem. Soc. 2011, 133, 7280-7283.

(2) (a) Garcia-Garibay, M. A. Proc. Natl. Acad. Sci. U.S.A. 2005, 102, 10771. (b) Khuong, T.-A. V.; Nunez, J. E.; Godinez, C. E.; GarciaGaribay, M. A. Acc. Chem. Res. 2006, 39, 413. (c) Karlen, S. D.; Reyes, H.; Taylor, R. E.; Khan, S. I.; Hawthorne, M. F.; Garcia-Garibay, M. A. Proc. Natl. Acad. Sci. U.S.A. 2010, 107, 14973. (d) Vogelsberg, V.; Garcia-Garibay, M. A. Chem. Soc. Rev. 2012, 41, 1892.

(3) (a) Setaka, W.; Yamaguchi, K. Proc. Natl. Acad. Sci. U.S.A. 2012, 109, 9271. (b) Setaka, W.; Yamaguchi, K. J. Am. Chem. Soc. 2012, 134, 17932. (c) Setaka, W.; Yamaguchi, K. J. Am. Chem. Soc. 2012, 134, 12458.

(4) (a) Zhang, W.; Xiong, R.-G. Chem. Rev. 2012, 112, 1163. (b) Zhang, Y.; Zhang, W.; Li, S.-H.; Ye, Q.; Cai, H.-L.; Deng, F.; 
Xiong, R.-G.; Huang, S. D. J. Am. Chem. Soc. 2012, 134, 1044. (c) Zhang, W.; Ye, H.-Y.; Graf, R.; Spiess, H. W.; Yao, Y.-F.; Zhu, R.Q.; Xiong, R.-G. J. Am. Chem. Soc. 2013, 135, 5230.

(5) (a) Horiuchi, S.; Tokunaga, Y.; Giovanetti, G.; Picozzi, S.; Itoh, H.; Shimano, R.; Kumai, R.; Tokura, Y. Nature 2010, 463, 789. (b) Akutagawa, T.; Koshinaka, H.; Sato, D.; Takeda, S.; Noro, S. I.; Takahashi, H.; Kumai, R.; Tokura, Y.; Nakamura, T. Nat. Mater. 2009, 8, 342. (c) Rabe, K. M.; Dawber, M.; Lichtensteiger, C.; Ahn, C. H.; Triscone, J.-M. Top. Appl. Phys. 2007, 105, 1.

(6) Lemouchi, C.; Mézière, C.; Zorina, L.; Simonov, S.; RodríguezFortea, A.; Canadell, E.; Wzietek, P.; Auban-Senzier, P.; Pasquier, C.; Giamarchi, T.; Garcia-Garibay, M. A.; Batail, P. J. Am. Chem. Soc. 2012, 134, 7880 .

(7) (a) Kottas, G. S.; Clarke, L. I.; Horinek, D.; Michl, J. Chem. Rev. 2005, 105, 1281. (b) Horinek, D.; Michl, J. Proc. Nat. Acad. Sci. U.S.A. 2005, 102, 14175. (c) Akimov, A. V.; Kolomeisky, A. B. J. Phys. Chem. C 2011, 115, 13584. (d) Masiero, S.; Lena, S.; Pieraccini, S.; Spada, G. P. Angew. Chem., Int. Ed. 2008, 47, 3184. (e) Kay, E. R.; Leigh, D. A.; Zerbetto, F. Angew. Chem., Int. Ed. 2007, 46, 72. (f) Feringa, B. L. Acc. Chem. Res. 2001, 34, 504.

(8) (a) Browne, W. R.; Feringa, B. L. Nat. Nanotechnol. 2006, 1, 25. (b) Horinek, D.; Michl, J. Proc. Natl. Acad. Sci. U.S.A. 2005, 102, 14175. (c) de Jonge, J. J.; Ratner, M. A.; de Leeuw, S. W. J. Phys. Chem. C 2007, 111, 3770. (d) Shirai, Y.; Morin, J.-F.; Sasaki, T.; Guerrero, J. M.; Tour, J. M. Chem. Soc. Rev. 2006, 35, 1043. (e) Tierney, H. L.; Baber, A. E.; Jewell, A. D.; Iski, E. V.; Boucher, M.; Sykes, E. C. H. Chem.-Eur. J. 2009, 15, 9678. (f) Garcia-Garibay, M. A. Angew. Chem., Int. Ed. 2007, 46, 8945.

(9) Chemistry of molecular rods: (a) Vögtle, F.; Frank, M.; Nieger, M.; Belser, P.; von Zelewky, A.; Balzani, V.; Barigelletti, F.; De Cola, L.; Flamigni, L. Angew. Chem., Int. Ed. Engl. 1993, 32, 1643. (b) Schwab, P. F. H.; Noll, B. C.; Michl, J. J. Org. Chem. 2002, 67, 5476. (c) Schwab, P. F. H.; Smith, J. R.; Michl, J. Chem. Rev. 2005, $105,1197$.

(10) Goldsmith, R. H.; Vura-Weis, J.; Scott, A. M.; Borkar, S.; Sen, A.; Ratner, M. A.; Wasielewski, M. R. J. Am. Chem. Soc. 2008, 130, 7659.

(11) Lemouchi, C.; Vogelsberg, C.; Simonov, S.; Zorina, L.; Batail, P.; Brown, S.; Garcia-Garibay, M. A. J. Am. Chem. Soc. 2011, 133, 6371.

(12) Lei, A.; Srivastava, M.; Zhang, X. J. Org. Chem. 2002, 67, 1969.

(13) Schwab, P. F. H.; Noll, B. C.; Michl, J. J. Org. Chem. 2002, 67, 5476.

(14) Kaleta, J.; Nečas, M.; Mazal, C. Eur. J. Org. Chem. 2012, 25, 4783.

(15) Kaleta, J.; Mazal, C. Org. Lett. 2011, 13, 1326.

(16) Duisenberg, A. J. M.; Kroon-Batenburg, L. M. J.; Schreurs, A. M. M. J. Appl. Crystallogr. 2003, 36, 220.

(17) Sheldrick, G. M. SADABS; University of Göttingen, Germany, 1996.

(18) Sheldrick, G. M. Acta Crystallogr., Sect. A 2008, 64, 112.

(19) Lemouchi, C.; Vogelsberg, C. S.; Zorina, L.; Simonov, S.; Batail, P.; Brown, S.; Garcia-Garibay, M. A. J. Am. Chem. Soc. 2012, 134, 13765.

(20) Hohenberg, P.; Kohn, W. Phys. Rev. 1964, 136, B864. Kohn, W.; Sham, L. J. Phys. Rev. 1965, 140, A1133.

(21) Zhao, Y.; Truhlar, D. G. Theor. Chem. Acc. 2008, 120, 215.

(22) Hariharan, P. C.; Pople, J. A. Theor. Chim. Acta 1973, 28, 213.

(23) Frisch, M. J.; Trucks, G. W.; Schlegel, H. B.; Scuseria, G. E.; Robb, M. A.; Cheeseman, J. R; Scalmani, G.; Barone, V.; Mennucci, B.; Petersson, G. A.; Nakatsuji, H.; Caricato, M.; Li, X.; Hratchian, H. P.; Izmaylov, A. F.; Bloino, J.; Zheng, G.; Sonnenberg, J. L.; Hada, M.; Ehara, M.; Toyota, K.; Fukuda, R.; Hasegawa, J.; Ishida, M.; Nakajima, T.; Honda, Y.; Kitao, O.; Nakai, H.; Vreven, T.; Montgomery J. A., Jr. ; Peralta, J. E.; Ogliaro, F.; Bearpark, M.; Heyd, J. J.; Brothers, E.; Kudin, K. N.; Staroverov, V. N.; Kobayashi, R,; Normand, J.; Raghavachari, K.; Rendell, A.; Burant, J. C.; Iyengar, S. S.; Tomasi, J.; Cossi, M.; Rega, N.; Millam, J. M.; Klene, M.; Knox, J. E.; Cross, J. B.; Bakken, V.; Adamo, C.; Jaramillo, J.; Gomperts, R.; Stratmann, R. E.; Yazyev, O.; Austin, A. J.; Cammi, R.; Pomelli, C.; Ochterski, J. W.; Martin, R. L.;
Morokuma, K.; Zakrzewski, V. G.; Voth, G. A.; Salvador, P.; Dannenberg, J. J.; Dapprich, S.; Daniels, A. D.; Farkas, Ö.; Foresman, J. B.; Ortiz, J. V.; Cioslowski, J.; Fox, D. J. Gaussian 09, Revision B1; Gaussian, Inc.: Wallingford, CT, 2009.

(24) Car, R.; Parrinello, M. Phys. Rev. Lett. 1985, 55, 2471.

(25) CPMD v3.15; MPI für Festkörperforschung: Stuttgart, Germany, 1997-2001; IBM Corp., 1990-2011.

(26) Liu, Q.; Burton, D. J. Tetrahedron Lett. 1997, 38, 4371.

(27) Lemouchi, C.; Barrès, A.-L.; Mézière, C.; Rondeau, D.; Zorina, L.; Wzietek, P.; Batail, P. Dalton Trans. 2011, 40, 8075.

(28) (a) Siemsen, P.; Levingston, R. C.; Diederich, F. Angew. Chem., Int. Ed. 2000, 39, 2632. (b) Rodriguez, J. G.; Diaz-Oliva, C. Tetrahedron 2009, 65, 2512.

(29) Yokozeki, A.; Kuchitsu, K.; Morino, Y. Bull. Chem. Soc. Jpn. 1970, 43, 2017.

(30) Ermer, O.; Dunitz, J. D. Helvetica Chem. Acta 1969, 52, 1861.

(31) Akutagawa, T.; Nakamura, T. Dalton Trans. 2008, 6335.

(32) Gabuda, S. P.; Kozlova, S. G.; Samsonenko, D. G.; Dybtsev, D. N.; Fedin, V. P. J. Phys. Chem. C 2011, 115, 20460.

(33) Jacques, J.; Collet, A.; Wilen, S. H. Enantiomers, Racemates, and Resolutions; Krieger: Malabar, FL, 1994.

(34) Behrnd, N.-R; Labat, G.; Venugopalan, P.; Hulliger, J.; Bürgi, H.-B. Cryst. Growth Des. 2010, 10, 52.

(35) Besara, T.; Jain, P.; Dalal, N. S.; Kuhns, P. L.; Reyes, A. P.; Kroto, H. W.; Cheetham, A. K. Proc. Natl. Acad. Sci. U.S.A. 2011, 108, 6828.

(36) Although there has been some evidence for SHG from centrosymmetric crystals, higher-order field-matter interaction mechanisms had to be invoked to explain its origin. Specifically, mechanisms that bring into the play electric-quadrupole or magnetic-dipole couplings of the medium with one of the photons involved in the process have been reported to be potential sources of symmetry-breaking effects, thereby generating weak, yet clearly detectable SHG signals from quadrupole ferroelectric or antiferromagnetic materials. See: (a) Van Elshocht, S.; Verbiest, T.; Kauranen, M.; Persoons, A.; Langeveld-Voss, B. M. W.; Meijer, E. W. J. Chem. Phys. 1997, 107, 8201. (b) Meijer, E. W.; Havinga, E. E.; Rikken, G. L. J. A. Phys. Rev. Lett. 1990, 65, 37. (c) Meijer, E. W.; Havinga, E. E. Synth. Met. 1993, 55-57, 4010. 